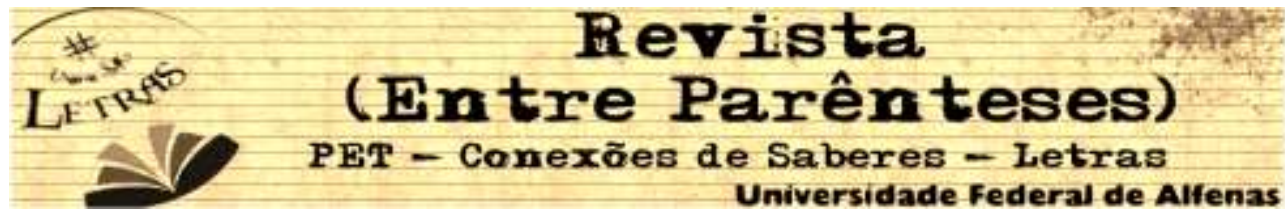

\title{
ANÁLISE NA PERSPECTIVA DISCURSIVA DA PERSONAGEM ALINE DE ADÃO ITURRUSGARAI
}

\author{
*Kátia Maria Capucci Fabri \\ Universidade de Uberaba-UNIUBE \\ (katia.fabri@uniube.br) \\ *Aline Leal de Sousa \\ (alineleal78@hotmail.com)
}

\begin{abstract}
Resumo: Este artigo verifica os modos como o sujeito Aline, personagem do cartunista Adão Iturrusgarai, constitui-se, discursivamente, sob os aspectos teórico-analíticos da Análise do Discurso francesa, analisando os efeitos de sentido pretendidos pelo autor bem como as formações ideológicas e discursivas presentes na materialidade verbo-visual das tiras em questão. A natureza da pesquisa é bibliográfica e qualitativa, sendo o material de análise constituído por duas tiras selecionadas em duas obras do autor. A escolha de Aline se deu pela heterogeneidade do discurso do sujeito em si. Nessa perspectiva, tece-se uma breve retrospectiva acerca da história da mulher para, então, ancorar-se nos fundamentos de Michel Pêcheux, a partir dos estudos dos estudos de Fernandes (2007), Mussalim (2003) e Orlandi (2001) acerca dos construtos da Análise do Discurso, tais como: discurso, sujeito do discurso, formação ideológica e discursiva, condições de produção, efeitos de sentido e interdiscurso (memória discursiva). Esses conceitos fornecem suporte para as análises da significação de Aline no contexto das tiras, possibilitando concluir que o sujeito em questão representa as conquistas femininas de maneira exagerada, pois subverte os discursos esperados pela sociedade no que se refere ao papel da mulher.
\end{abstract}

PALAVRAS-CHAVE: Discurso; Tiras; Efeitos de Sentido.

ABSTRACT: This article broaches the manner how the subject Aline, a character of the cartoonist Adão Iturrusgarai is constituted discursively under the theoretic-analytical aspects of the French Discourse Analysis, with the intention of verifying the effects of meaning intended by the author, as well as the ideological and discursive formations present in the written-visual materiality of the strips in question. The research is of bibliographical and qualitative nature, and the material analyzed is made up of two cartoon strips selected from two of the author's books. The choice of Aline happened due to the heterogeneity of the subject's discourse. In this perspective, a brief retrospective of the woman's history is presented, and then anchored to the fundaments of Michel Pêcheux in the studies of Fernandes (2007), Mussalim (2003) and Orlandi (2001) concerning the constructs of Discourse Analysis, such as: discourse, discourse subject, effects of meaning and interdiscourse (discursive memory). These concepts offer support for the analysis of meaning of Aline in the context of the strips, allowing for conclusions concerning the subject under study: she represents the female conquests in an exaggerated manner, as she subverts discourses expected by society relating to the woman's role.

"Kátia Maria Capucci Fabri, Doutorado em Estudos Linguísticos (UFU), Docente na UNIUBE - Uberaba, katia.fabri@uniube.br; * Aline Leal de Sousa, Egressa do curso de Letras da FAZU, Uberaba/MG. alineleal78@hotmail.com

Revista (Entre Parênteses) Volume 1, Número 5, 2016 - ISSN 2238-4502 


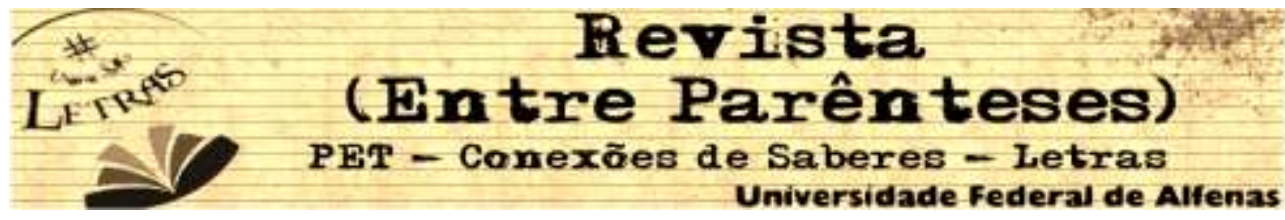

KEY WORDS: Discourse; Strips; Effects of Meaning.

\section{INTRODUÇÃO}

As palavras no discurso evidenciam aspectos ideológicos e históricos próprios à existência dos discursos nos diferentes contextos sociais.

Nessa concepção, este estudo se justifica pelo fato de o discurso da personagem Aline, do cartunista Adão Iturrusgarai, romper com vários paradigmas da mulher na sociedade machista, o que motivou as pesquisadoras a examinarem como a emancipação feminina é retratada nas tiras de humor dessa personagem. A partir disso, definiu-se o objetivo geral que se concentra em verificar os modos como o sujeito-personagem, Aline, constitui-se discursivamente, sob os aspectos teóricoanalíticos da Análise do Discurso (doravante $A D$ ) francesa, na materialidade verbovisual do contexto das tiras em estudo.

Para se chegar ao objetivo principal, parte-se para uma análise qualitativa de duas tiras da personagem, selecionadas em duas obras do autor com o intuito de (i) observar os diferentes elementos que compõem as tiras, tais como enunciados, temas abordados, imagens e que contribuem para a construção da identidade da mulher; (ii) verificar os efeitos de sentido pretendidos pelo autor; (iii) analisar as construções ideológicas e discursivas presentes na cena de enunciação da personagem Aline, a fim de relacioná-las com os valores, historicamente, definidos pela sociedade no que se refere ao estereótipo da mulher.

Diante desse contexto, define-se o que vem a ser a cena de enunciação fundamentada por Dominique Maingueneau, aqui, nas palavras de Guimarães (2005, p. 23):

[...] uma cena enunciativa se caracteriza por constituir modos específicos de acesso à palavra, dadas as relações entre as figuras da enunciação e as formas linguísticas. [...] A cena enunciativa é assim um espaço particularizado por uma deontologia específica de distribuição dos lugares de enunciação no acontecimento. [...] São lugares constituídos pelos dizeres e não pessoas donas do seu dizer. Assim estudá-la é necessariamente considerar o próprio modo de constituição destes lugares pelo funcionamento da língua. 


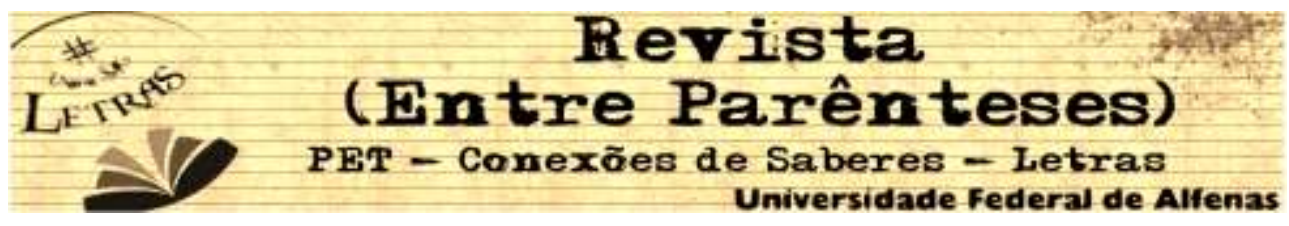

Para alcançar os objetivos propostos, considera-se o número de duas tiras suficiente. Busca-se, a partir das análises feitas, responder às seguintes questões: (i) De que forma os diferentes elementos que compõem as tiras, tais como enunciados, temas abordados, imagens contribuem para a construção da identidade do sujeito Aline?; (ii) Quais são os efeitos de sentido pretendidos pelo autor das tiras?; (iii) De que modo as construções ideológicas e discursivas presentes na cena de enunciação da personagem Aline se relacionam com os valores, historicamente, definidos pela sociedade no que se refere ao estereótipo da mulher?

Quanto às hipóteses, percebe-se que o sujeito em análise foi construído de uma maneira atípica da forma com que as mulheres são, geralmente, retratadas em veículos de humor, pois representa as conquistas femininas de uma maneira exacerbada e despudorada. As tiras retomam, ainda, a ideia de que as mulheres são mais complexas que os homens, haja vista Aline ocupar o lugar do homem em uma relação conjugal poligâmica, ao mesmo tempo em que dialoga com os problemas típicos do universo feminino. Nesse sentido, o autor confirma essas conquistas sem lançar mão da sensibilidade e complexidade características desse ser, as quais foram estimuladas pelas circunstâncias históricas e culturais.

A escolha das tiras de Aline se deu, portanto, por abordar um discurso contraditório de uma jovem que, paradoxalmente, navega entre a contemporaneidade, às vezes libidinosa, das conquistas femininas e o tradicionalismo da visão machista da mulher bem como os discursos correntes a respeito da mulher e de seu (esperado) papel.

\section{Considerações teóricas}

Não é bom que o homem esteja só; vou dar-lhe uma ajuda que lhe seja adequada. Então o Senhor Deus mandou ao homem um profundo sono; e enquanto ele dormia, tomou-Ihe uma costela e fechou com carne o seu lugar. E, da costela que tinha tomado do homem, o Senhor Deus fez uma mulher e levou-a para junto do homem. (GẾNESIS 2, $18 ; 21-2$, p. 50)

Desde o milagre da criação, experimenta-se certo domínio da figura masculina, uma vez que a origem da mulher se deu, segundo os relatos bíblicos, 


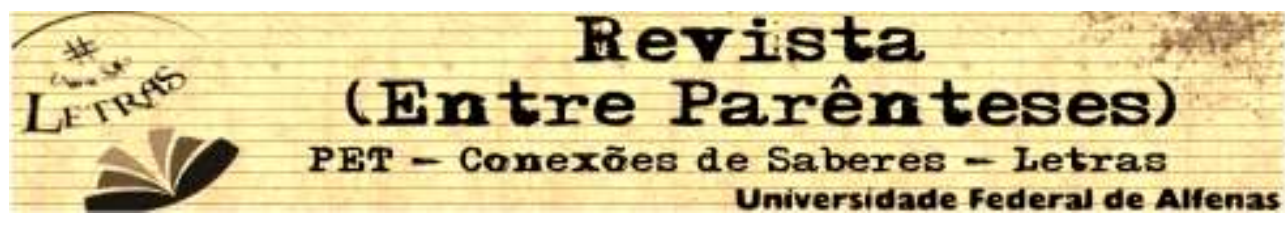

porque o homem se sentia só. Já no Paraíso, porém, foram advertidos a não comerem o fruto da árvore da ciência do bem e do mal sob pena de perecerem. Todavia, a mulher, cedendo à astúcia da serpente, não apenas experimentou o fruto proibido, como, ainda, apresentou-o ao companheiro que o fez igualmente. Logo, sob a compreensão mística da criação, a figura feminina é inferiorizada, pois fora criada para satisfazer a solidão do varão, além de responsabilizada por instituir o pecado original por meio de sua desobediência.

$\mathrm{Na}$ era primitiva, contudo, pode-se dizer, segundo Aquino (2008), que a relação entre homem e mulher decorreu de maneira mais equilibrada, visto que ambos desempenhavam a mesma função social de prover, essencialmente, a alimentação do clã.

Na fase pré-capitalista, o mundo do trabalho e o mundo doméstico, de acordo com pesquisa de Bessa (2007), eram coincidentes, já que todos trabalhavam numa mesma unidade econômica de produção. Todavia, a função reprodutora da mulher, além de favorecer sua subordinação ao homem, subjugou-a à incapacidade de assumir a direção e chefia do grupo familiar. Essa circunstância, associada à imagem do homem e de sua força física, permitiu a ele apropriar-se do poder dentro da sociedade. Dessa forma, surgiram as sociedades patriarcais fundamentadas no poder do chefe de família. Nesse cenário, a sexualidade da mulher foi sendo, cada vez mais, submetida aos interesses masculinos de reprodução de sua descendência e sua função foi se restringindo ao mundo doméstico. Para Beauvoir (1949), a vida doméstica conduziu a mulher a olhar mais para o interior de si mesma.

Ela [a mulher] tem uma preocupação extremada por tudo que ocorre dentro dela; é desde o início muito mais opaca a seus próprios olhos, mais profundamente assaltada pelo mistério perturbador da vida que o homem. (BEAUVOIR, 1949, p. 20)

$\mathrm{Na}$ sociedade capitalista, ainda de acordo com Bessa (2007), persistiu o argumento da diferença biológica como base para a desigualdade entre homens e mulheres. As mulheres eram vistas como menos capazes que os homens e o adultério 


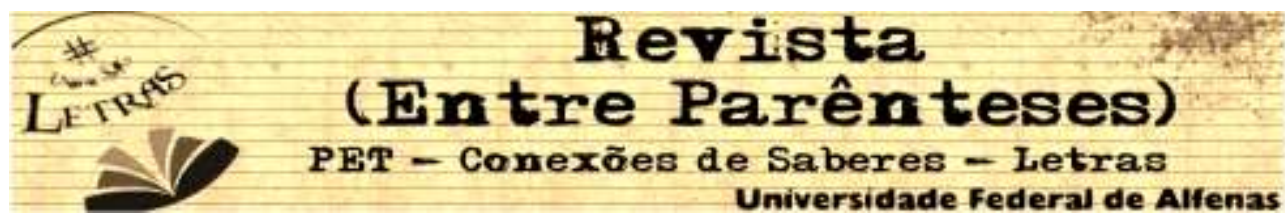

era crime gravíssimo, pois colocava em perigo a legitimidade da prole como herdeira da propriedade do homem.

Assim, a partir desse panorama da evolução da condição da mulher na sociedade, é que se pretende realizar, na perspectiva da $A D$, um estudo preliminar, a fim de observar como os aspectos sociais, ideológicos e históricos do discurso feminino são discutidos nas tiras de humor de Aline.

A Análise do Discurso considera como parte constitutiva do sentido o contexto-histórico. (...) O contexto histórico-social, então, o contexto de enunciação, constitui parte do sentido do discurso e não apenas um apêndice que pode ou não ser considerado. Em outras palavras, pode-se dizer que, para a $A D$, os sentidos são historicamente construídos. (MUSSALIM, 2003, p. 123)

Em Bakhtin (1992), todo enunciado só pode ser entendido no interior de um gênero discursivo. A tira, neste estudo, é compreendida como um gênero textual. Portanto, faz-se necessário uma breve definição do gênero tiras.

As tiras são um subtipo de HQ (históras em quadrinho); mais curtas (até 4 quadrinhos) e, portanto, de caráter sintético, podem ser sequenciais (capítulos de narrativas maiores) ou fechadas (um episódio por dia). Quanto às temáticas, algumas tiras também satirizam aspectos econômicos e políticos do país, embora não sejam tão "datadas" como a charge. Dividimos as tiras fechadas em dois subtipos: a) tiras-piadas, em que o humor é obtido por meio das estratégias discursivas utilizadas nas piadas de um modo geral, como a possibilidade de dupla interpretação, sendo selecionada pelo autor a menos provável; b) tiras-episódio, nas quais o humor é baseado especificamente no desenvolvimento da temática numa determinada situação, de modo a realçar as características das personagens (...). Podemos, então, caracterizar provisoriamente a HQ como um gênero icônico ou icônico verbal narrativo cuja progressão temporal se organiza quadro a quadro. Como elementos típicos, a HQ apresenta os desenhos, os quadros e os balões e/ou legendas, onde é inserido o texto verbal. (MENDONÇA, 2002, p. 199)

As tiras de Aline se configuram no subtipo tiras-episódio e estando inseridas no discurso humorístico, elas apresentam as conquistas femininas e a liberdade alcançada pela mulher de forma caricaturada. 


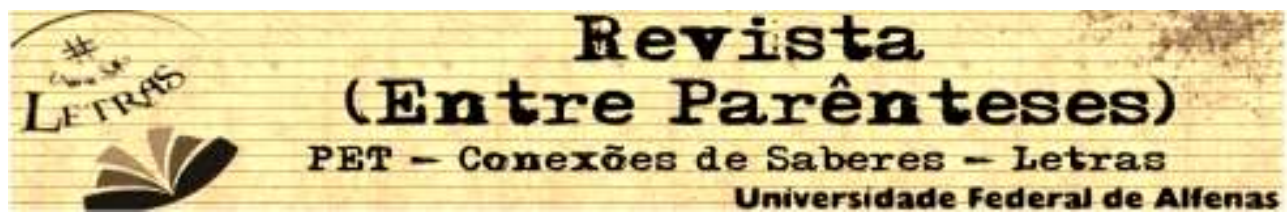

\begin{abstract}
Aline é que é mulher de verdade. Trabalha fora de casa, odeia cozinhar e arrumar a casa e tem DOIS maridos. Ela divide a cama com Otto e Pedro. Os três se amam, mas isso não impede que Aline procure diversão fora do lar. Dizem as más línguas que Aline é ninfomaníaca, tarada sexual. Já as boas línguas preferem dizer que ela é uma mulher normal e simplesmente "dá vazão livre a seus instintos sexuais." (ITURRUSGARAI, 2006, contracapa)
\end{abstract}

A priori, busca-se posicionar a Análise do Discurso de vertente francesa enquanto disciplina da qual depreende esse artigo e cujo objeto de estudo é o discurso. A AD surge no final da década de 60 , a partir dos estudos precursores do francês Michel Pêcheux.

Para a $A D$ o conceito de discurso não se resume a seu emprego cotidiano para efetuar referência a pronunciamentos retóricos orientados, como os discursos políticos ou a um texto elaborado a partir de recursos estilísticos mais rebuscados. Vai além, pois como objeto de investigação científica, rompe com as acepções do senso comum.

Inicialmente, podemos afirmar que discurso, tomado como objeto da Análise do Discurso, não é a língua, nem texto, nem a fala, mas que necessita de elementos linguísticos para ter uma existência material. (FERNANDES, 2007, p. 18)

A partir da definição de Fernandes (2007), compreende-se que o discurso ultrapassa os limites da língua. Sendo exterior a ela, envolve questões sociais e ideológicas e, não, as estritamente linguísticas.

Enquanto uma teoria de leitura em que não se separam forma e conteúdo, a língua não pode ser compreendida como uma estrutura apenas e, sim, como um acontecimento no qual são considerados os sujeitos, suas inscrições na história e as condições de produção da linguagem. Desse modo, o diálogo estabelecido entre as áreas do saber procura mostrar que a ideologia tem existência material e é na linguagem que ela se materializa.

Para Orlandi (2001, p. 15), "o discurso é assim palavra em movimento, prática de linguagem: com o estudo do discurso observa-se o homem falando". Nessa perspectiva, ao partir-se para as análises das tiras de Aline, pretende-se identificar 


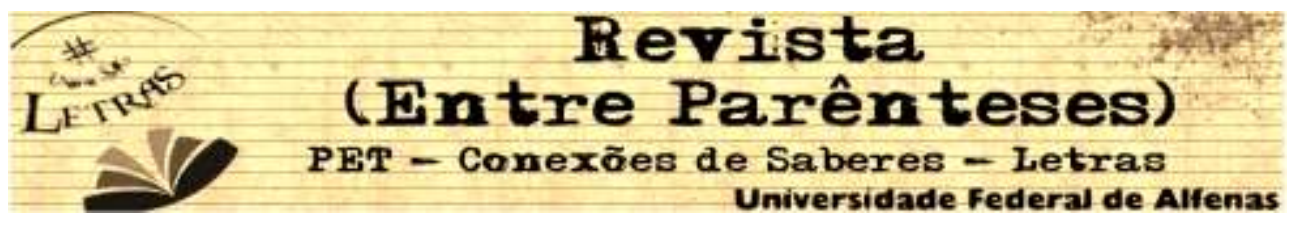

tais questões nas escolhas lexicais realizadas pela personagem (interpretá-la falando), porque essas expressam a língua fazendo sentido enquanto constitutiva do homem e de sua história.

As escolhas lexicais e seu uso revelam a presença de ideologias que se opõem, revelando igualmente a presença de diferentes discursos, que, por sua vez, expressam a posição de grupos de sujeitos acerca de um mesmo tema. (FERNANDES, 2007, p. 19)

Como este estudo está pautado nos conceitos basilares da $A D$, faz-se necessário uma breve caminhada por eles, visto que os mesmos serão úteis nas futuras reflexões em torno das tiras selecionadas.

Iniciando pelo sujeito discursivo, depara-se com o conceito de polifonia, apresentado, pioneiramente, por Mikhail Bakhtin e definido, simplificadamente, como um conjunto de outras vozes que se manifestam no dizer do sujeito constituído na interação social. Ao observar a heterogeneidade de discursos que emanam do sujeito discursivo Aline, verifica-se que ela não é o centro de seu dizer, pois seu discurso está marcado por diferentes vozes sociais.

Em toda parte um determinado conjunto de ideias, pensamentos e palavras passa por várias vozes imiscíveis, soando em cada uma de modo diferente. (Bakhtin, 2008 apud PIRES; TAMANINI-ADAMES, 2010, p. 71)

Nesse sentido, captam-se, nas tiras, algumas contradições, as quais assombram o próprio sujeito Aline, visto que a personagem transita entre as conquistas femininas e os discursos recorrentes a respeito da mulher, e, nessas histórias, ressurgem os discursos típicos sobre o sexo feminino.

Para expressar sua ideologia, o sujeito faz uso do discurso. De acordo com Orlandi (2001. p. 44), "as palavras mudam de sentido de acordo com as posições ideológicas daqueles que as empregam."

Para Mussalim (2003, p. 131),os sentidos possíveis de um discurso são preestabelecidos pela identidade das formações discursivas. Entretanto, eles não

$7 \frac{\text { Revista (Entre Parênteses) }}{\text { Volume 1, Número 5, 2016 - ISSN 2238-4502 }}$




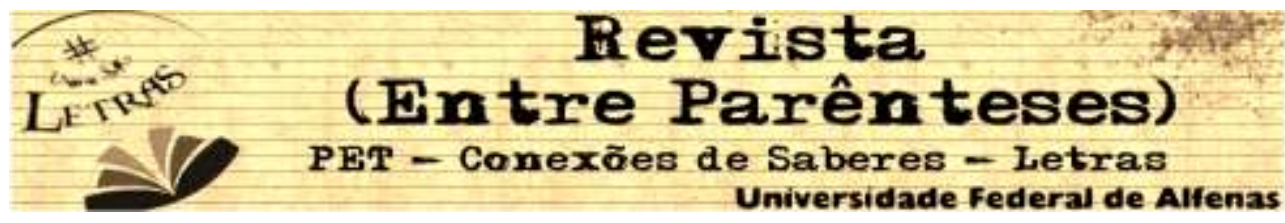

existem antes do discurso, eles vão sendo determinado simultaneamente às posições ideológicas.

É pela referência à formação discursiva que, em Orlandi (2001, p. 44), "podemos compreender, no funcionamento discursivo, os diferentes sentidos. Palavras iguais podem significar diferentemente porque se inscrevem em formações discursivas diferentes." Assim, segundo Pêcheux (1997 apud FERNANDES,2007, p. 22), o significado de uma expressão não existe "em si mesmo", porém é determinado pelas posições ideológicas colocadas em jogo no processo sócio-histórico.

A exterioridade do discurso exige que o analista rompa com as estruturas linguísticas. Todavia, ao romper a barreira da língua e chegar ao contexto social, o estudioso da $A D$ se depara com posições divergentes, ou seja, diferentes discursos concomitantes que coexistem, pois há diferenças ideológicas dos interlocutores em um mesmo espaço, daí os conflitos e contradições.

A construção de um discurso pelo sujeito depende de suas condições de produção que são os aspectos históricos, sociais e ideológicos que possibilitam a construção do discurso.

Podemos considerar as condições de produção em sentido estrito e temos as circunstâncias da enunciação: é o contexto imediato. E se as consideramos em sentido amplo, as condições de produção incluem o contexto sócio-histórico, ideológico. (ORLANDI, 2001, p. 30)

Sob a ótica da $A D$, o sentido das tiras de humor, que são o objeto deste estudo, deve ser entendido como efeitos do interdiscurso, vinculado a uma memória discursiva, tendo em vista os discursos correntes a respeito da mulher e de seu (esperado) papel. Para essa análise, verificam-se as condições de produção que compreendem, fundamentalmente, os sujeitos e a situação.

(...) é a relação que os analistas do discurso procuram estabelecer entre um discurso e suas condições de produção, ou seja, entre um discurso e as condições sociais e históricas que permitiram que ele fosse produzido e gerasse determinados efeitos de sentido e não outros. (MUSSALIM, 2003, p. 112) 


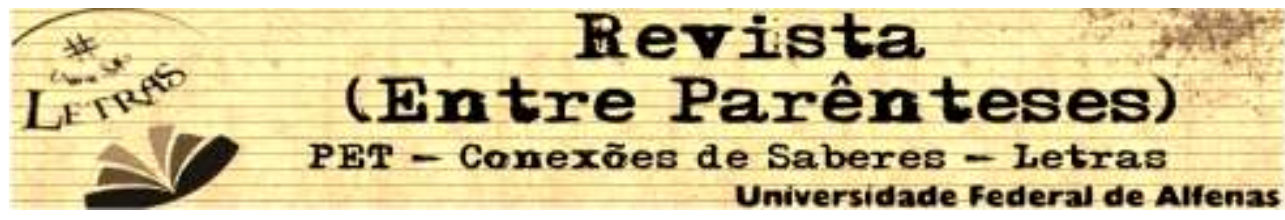

Nas palavras de Pêcheux (1997 apud LIMA, 2011, p. 29), entre os sujeitos o que se transmite, além de informação, é um leque de "efeito de sentidos". No que se refere à noção de sentido, a qual se trata do efeito de sentidos pretendido pelos sujeitos em interlocução, busca-se apreender a ideologia desses, ou seja, a forma como compreendem a realidade social, histórica e política na qual estão inseridos.

Em Fernandes (2007), constata-se que os sentidos são produzidos conforme os lugares socioideológicos ocupados por aqueles em interlocução.

O sujeito passa a ser concebido como aquele que desempenha diferentes papéis de acordo com as várias posições que ocupa no espaço interdiscursivo. (...) O sujeito apesar de desempenhar diversos papéis, não é totalmente livre; ele sofre as coerções da formação discursiva do interior do qual já enuncia, já que esta é regulada por uma formação ideológica. (MUSSALIM, 2003, p. 133)

A memória discursiva pode ser tomada como "o saber discursivo que torna possível todo dizer e que retorna sob a forma do pré-construído" (Orlandi, 2001, p. 31), todavia, pensada em relação ao discurso, é tratada como interdiscurso.

O interdiscurso é todo o conjunto de formulações feitas e já esquecidas que determinam o que dizemos. Para que minhas palavras tenham sentido é preciso que elas já façam sentido. $E$ isto é efeito do interdiscurso: é preciso que o que foi dito por um sujeito específico, em um momento particular se apague na memória, para que, passando para o "anonimato", possa fazer sentido em "minhas" palavras. (ORLANDI, 2007, p. 33)

O ato de ler para Brandão e Micheletti (2002, p. 9):

É um processo abrangente e complexo; é um processo de compreensão, de intelecção de mundo que envolve uma característica essencial e singular ao homem: a sua capacidade simbólica e de interação com outro pela mediação de palavras. $O$ ato de ler não pode se caracterizar como uma atividade passiva.

Ler não é, pois decodificar, traduzir, repetir sentidos dados como prontos, é construir uma sequência de sentidos a partir dos índices que o sentido do autor quis 


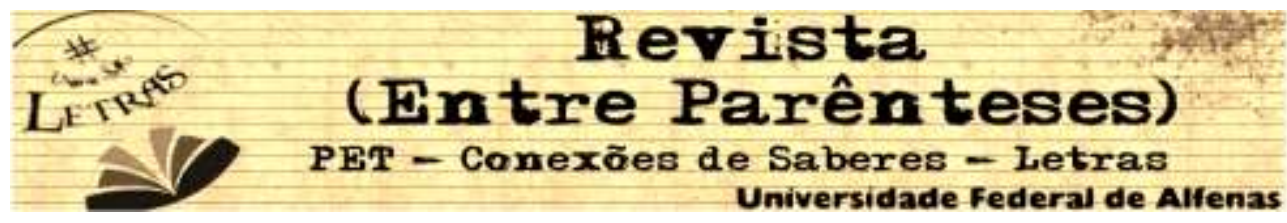

dar a seu texto. É através do ato de ler que o homem interage com os outros homens por meio da palavra escrita. O leitor é um ser ativo que dá sentido ao texto. A palavra escrita ganha significados a partir da ação do leitor sobre ela.

Em suma, a Análise de Discurso visa à compreensão de como um objeto simbólico produz sentidos, como ele está investido de significância para e por sujeitos. Essa compreensão, por sua vez, implica explicitar como o texto organiza os gestos de interpretação que relacionam sujeito e sentido. Produzem-se assim novas práticas de leitura. (ORLANDI, 2001, p. 27) de análise.

A seguir, apresentamos a metodologia adotada neste estuso e o nosso material

\title{
Considerações metodológicas
}

Quanto ao material e método deste estudo, pode-se dizer que ele é de natureza bibliográfica, abrangendo concepções da Análise do Discurso de origem francesa e a compreensão de tiras como gênero textual e de natureza qualitativa.

\begin{abstract}
A abordagem qualitativa parte do fundamento de que há uma relação dinâmica entre o mundo real e o sujeito, uma interdependência viva entre esse sujeito e o objeto, um vínculo indissociável entre o mundo objetivo e a subjetividade do sujeito. O conhecimento não se reduz a um rol de dados isolados, conectados por uma teoria explicativa; o sujeito observador é parte integrante do processo de conhecimento e interpreta os fenômenos, atribuindo-lhes um significado. O objeto não é dado inerte e neutro; está possuído de significados e relações que sujeitos concretos criam sem suas ações. (CHIZZOTTI, 2000, p. 79)
\end{abstract}

Já no que refere ao corpus do artigo, ele compõe-se de duas tiras da personagem Aline, as quais serão analisadas, qualitativamente

Falando-se da personagem em foco - Aline, essa foi concebida pelo cartunista gaúcho, Adão Iturrusgarai. Nascido em 1965, em Cachoeira do Sul, publicou o primeiro cartum em um jornal de sua cidade natal. Na década de 80 , editou as revistas Megazine e Dundun. Em 1993, começou a publicar na Folha de São Paulo com Angeli, Laerte e Glauco, fazendo as tiras Los 3 amigos. A partir de 1996, iniciou 


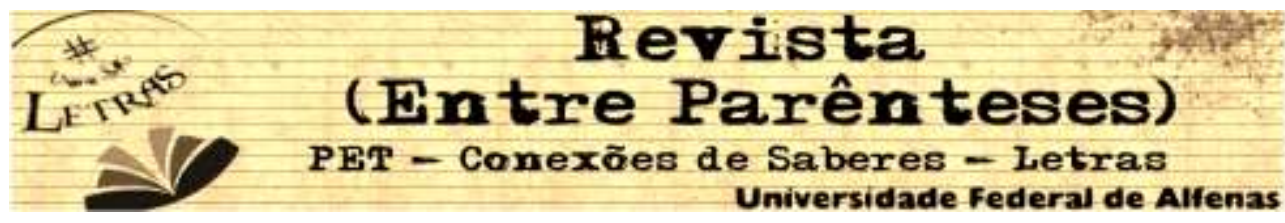

carreira solo com Aline. É, também, autor dos caubóis gays Rock e Hudson. Trabalhou ainda como redator de programas humorísticos da Rede Globo, como TV Colosso e Casseta \& Planeta. Em 2007, mudou-se para a Argentina e começou a publicar na revista Fierro. Em 2009, vendeu os direitos de Aline para a Rede Globo e a personagem virou minissérie, por uma temporada. $O$ material de análise foi retirado de duas obras do referido autor:1. Aline: cama, mesa e banho. São Paulo: Devir, 2002. Aline: antrologia. Porto Alegre, RS: L\&PM, 2011.

O material de análise foi retirado de duas obras do referido autor:

1. Aline: cama, mesa e banho. São Paulo: Devir, 2000.

2. Aline: antrologia. Porto Alegre, RS: L\&PM, 2011.

\section{Resultados e discussões}

A partir dos construtos teóricos da $A D$, passamos à análise de duas tiras selecionadas em duas obras de Adão Iturrusgarai citadas anteriormente.

Na primeira tira selecionada, o sujeito Aline se encontra em um dilema pessoal. No primeiro quadrinho, ela está em frente ao espelho, com uma feição que demonstra certa decepção consigo mesma, fazendo a si uma pergunta: "DEVO OU NÃO DEVO TRANSAR COM MEU PSIQUIATRA?" Nota-se que o advérbio "não" está em negrito, sinalizando para o fato de que o correto seria que o relacionamento não se efetivasse. Esse questionamento não apenas faz emergir a memória discursiva como, também, desestabiliza-a, uma vez que promove o embate entre o estereótipo da mulher que é o de ter que manter um relacionamento monogâmico estável e a questão da infidelidade ou busca pela satisfação dos prazeres da carne. Além disso, o fato de o parceiro ser o seu psiquiatra indica que Aline vive dilemas pessoais que necessitam ser equalizados com auxílio profissional. Tal perspectiva promove o interdiscurso com a questão da complexidade feminina fixada como uma verdade na sociedade.

No segundo quadrinho, o sujeito discursivo responde à pergunta que fizera a si mesmo com os adjetivos: "É FEIO, É SUJO, É PERVERSO, É PROIBIDO, IMORAL, INDECENTE, ANTI-ÉTICO, IRRESPONSÁVEL...” Esse cenário induz à imaginação 


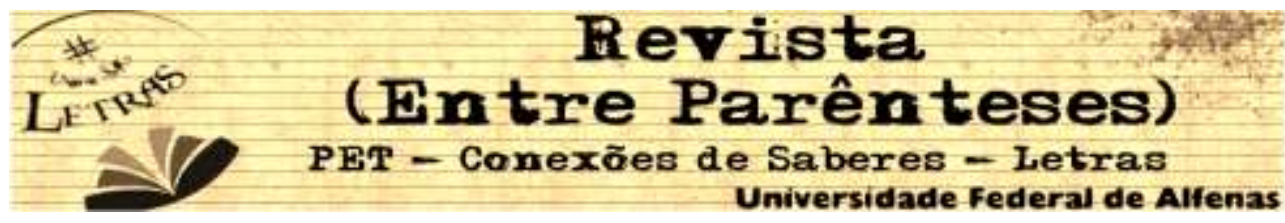

de que Aline, realmente, entende como errado ter um relacionamento sexual com seu psiquiatra, pois enumera vários pontos para dissuadi-la. O adjetivo "perverso" se encontra destacado e ao se recorrer aos seus sinônimos dicionarizados, verifica-se que o mesmo pode ser malicioso, o que fará sentido no terceiro quadrinho. Os impedimentos elencados se encontram no inconsciente do sujeito, comprovando que mesmo sendo uma mulher, libidinosamente, bem resolvida, Aline provoca, automaticamente, um ajustamento dela própria a uma ideologia, revelando traços de elementos discursivos anteriores.

No último quadrinho, a conclusão de Aline subverte a situação ao apresentar um discurso contrário ao esperado. Em "OU SEJA, DEVE SER MUITO GOSTOSO!!", ela rompe com os estereótipos, os tradicionalismos, os preconceitos, isto é, com o papel esperado da mulher. $O$ destaque agora é para o advérbio "muito" para enfatizar que o fato de ser proibido deixaria o relacionamento com um sabor especial, o que pode ser constatado por meio da feição maliciosa de Aline.

Nota-se, nessa tira, um embate ideológico que o sujeito trava consigo mesmo e, por se tratar de um gênero de humor, vence o não óbvio. Nesse contexto, o efeito pretendido pelo autor é apresentar a emancipação sexual feminina. A mulher que antes se casava cedo e dedicava a vida ao marido e aos filhos se liberta e se permite realizar fantasias e desejos ou, pelo menos, tê-los.

Portanto, há que se analisarem as condições de produção, pois para Pêcheux (1997) é impossível analisar um discurso como um texto, isto é, como uma sequência linguística fechada sobre si mesma, [...] é necessário referi-lo ao conjunto de discursos possíveis.

Outro material analisado, que faz parte do corpus, foi retirado da obra "Aline: antropologia" (2011). Nessa tira, a personagem Aline decide fundar uma religião e desse contexto surge a tira que analisamos a seguir. Sabe-se que, desde os primórdios, a ideia de pecado está, intimamente, ligada à religião e, de certa forma, à humanidade e, por isso, encontra-se no inconsciente de cada um, haja vista a perspectiva cristã da criação do homem ter dominado, por séculos, a história da humanidade. Nesse sentido, Orlandi (2001, p. 47) diz que o sentido da língua 


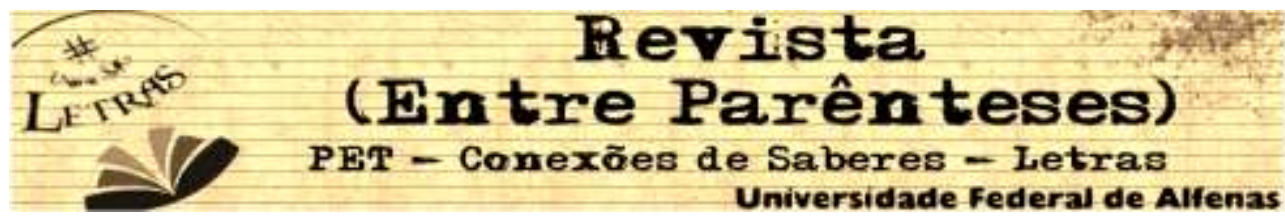

necessita de que a história intervenha pelo equívoco, pela opacidade. Disso resulta que a interpretação é regulada pelas possibilidades, em suas condições.

No primeiro quadrinho, da tira em análise, Aline e seus dois namorados caminham pela rua quando um deles a questiona: "E NA SUA RELIGIÃO, ALINE... VAI EXISTIR PECADO?" O substantivo "pecado" em negrito demonstra toda a carga negativa por trás do ato de violar as leis divinas. Como quase toda religião dialoga com a noção de pecado, espera-se que, para instaurar o humor, a resposta de Aline seja negativa, haja vista o que já se conhece do discurso vanguardista do sujeito em questão. Entretanto, sua reação surpreende os companheiros quando ela anuncia: "MAS É CLARO...". Considerando a ideologia da personagem, o discurso de Aline no segundo quadrinho toma um sentido oposto ao esperado por um sujeito que procura romper com estereótipos-padrão e paradigmas tradicionais. Esse gesto sinaliza para as marcas do passado que a garota traz consigo, comprovando que o sujeito estabelece comunicação com esses traços anteriores por meio da memória discursiva que é inerente ao sujeito, porque reside no seu inconsciente. Ou seja, o sujeito não é dono de seu discurso.

No terceiro quadrinho, Aline transgride, porém, os paradigmas da educação sexual cristã ao dar continuidade às reticências que deixou em seu discurso anterior: "VAI SER UM PECADO FAZER SEXO SÓ COM UMA PESSOA!". Com esse discurso, o sujeito desestabiliza, mais uma vez, a memória resgatada, subvertendo as marcas desse passado cristão que, inconscientemente, leva consigo, no qual o sexo é visto sob uma perspectiva pecaminosa, pois sua função não é o prazer e sim a procriação e, portanto, deve acontecer, com essa finalidade, entre duas pessoas apenas, de sexos opostos, as quais devem ser fiéis umas às outras até que a morte as separe.

Logo, analisando as condições de produção dessa tira, depreende-se que o efeito de sentido perseguido pelo autor, nesse contexto, é o de promover o diálogo sobre a emancipação sexual feminina, visto que muitas mulheres foram educadas para o casamento e não se permitem uma liberdade sexual em busca da satisfação pessoal. 


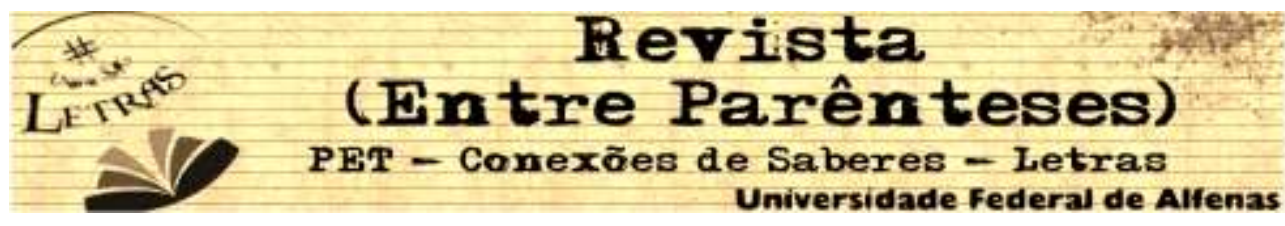

\section{Considerações finais}

As tiras de humor, apesar de sua aparente simplicidade, constituem-se um importante material de análise, pois podem permitir, através de sua materialidade verbo-visual, ricas discussões acerca de temáticas variadas.

Sob a perspectiva da Análise do Discurso de linha francesa, analisou-se, nesse estudo, duas tiras de Aline, do cartunista Adão Iturrusgarai, nas quais constataram-se os efeitos do interdiscurso no que se referem à retomada da memória discursiva a respeito da mulher e de sua evolução na sociedade.

A personagem Aline se apresenta como um sujeito discursivo complexo, promovendo o diálogo entre a mulher do passado e a mulher contemporânea que abdica da vida doméstica para disputar espaço no mercado de trabalho e que adota posições ideológicas bem diferentes das impostas pela sociedade machista. Verificase, a todo o momento, um embate entre as conquistas femininas e o estereótipo padrão (papel esperado) da mulher.

Diante desse panorama, pode-se constatar que as escolhas lexicais e seu uso no discurso revelam a presença das ideologias da personagem, e, por outro lado, comprovam que o sujeito não é homogêneo, haja vista suas palavras estarem impregnadas de aspectos sociais, históricos e ideológicos.

Ao analisar as construções ideológicas e discursivas presentes na cena de enunciação da personagem, comprova-se que ela subverte, em seu discurso, o papel esperado da mulher. Por ser um gênero humorístico, a personagem-sujeito trata das conquistas da mulher de uma maneira exagerada, quebrando paradigmas e discutindo temas tabus ao universo feminino, como libertação sexual, fidelidade e religião.

Assim, Aline representa o extremo da independência feminina, pois assume de uma mulher transgressora que dá vazão às suas vontades e desejos mais íntimos.

\section{REFERÊNCIAS}

AQUINO, R. S. L. de et al. História das sociedades: das comunidades primitivas às sociedades medievais. Rio de Janeiro (RJ): Imperial Novo Milênio, 2008. 


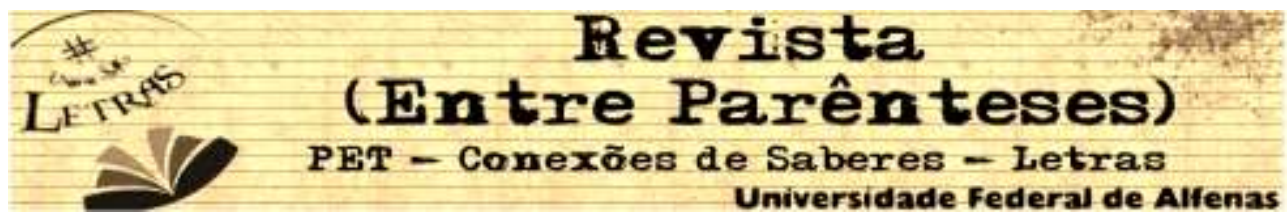

BAKHTIN, M. Estética da criação verbal. São Paulo: Martins Fontes, 1992.

BEAUVOIR, S. O Segundo Sexo - A experiência vivida. Rio de Janeiro (RJ): Nova Fronteira, vol. 2, 1949.

BESSA, K. A. M. O papel da mulher na sociedade ao longo da história. 2007. Disponível em: <

http://estelavieira-uminho.blogspot.com.br/2009/08/o-papel-da-mulher-na-sociedadeao-longo.html>. Acesso em: 19 nov. 2013.

BÍBLIA SAGRADA. São Paulo (SP): Ave-Maria, 43. ed., Edição Claretiana, 2003.

BRANDÃO, H. H. N.; MICHELETTI, G. Teoria e prática da leitura. In: Coletânea de textos didáticos. Componente curricular leitura e elaboração de textos. Curso de Pedagogia em Serviço. Campina Grande: UEPB, 2002.

FERNANDES, C. A. Análise do Discurso: Reflexões Introdutórias. São Carlos (SP): Claraluz, 2. ed., 2007.

GUIMARÃES, E. Os limites do sentido: um estudo histórico e enunciativo da linguagem. Campinas (SP): Pontes, 2005.

ITURRUSGARAI, A. Aline: antrologia. Porto Alegre (RS): L\&PM, 2011.

ITURRUSGARAI, A. Aline - TPM - tensão pré-monstrual. Porto Alegre (RS):

L\&PM, 2006.

ITURRUSGARAI, A. Aline: cama, mesa e banho. São Paulo: Devir, 2000.

LIMA, V. B. de. A Jovem mulher contemporânea urbana e os efeitos de sentido na discursividade da série televisiva Aline. 2011. 141 f. Dissertação (mestrado) Universidade Estadual de Maringá, Centro de Ciências Humanas, Letras e Artes, Programa de Pós-Graduação em Letras Disponível em: < http://www.ple.uem.br/defesas/pdf/vblima.pdf>. Acesso em: 19 nov. 2013.

MENDONÇA, M. R. de S. Um gênero quadro a quadro: a história em quadrinhos. In: DIONISIO, A. P.; MACHADO, A. R. \& BEZERRA, M. A. (orgs.). Gêneros textuais \& Ensino. Rio de Janeiro: Lucerna, 2002.

MUSSALIM, F. Análise do Discurso. In: MUSSALIM, F.; BENTES, A. C. (org.). Introdução à Linguística: domínios e fronteiras. Vol. II, 3. ed. São Paulo: Cortez, 2003, Cap. 1, p. 13-52.

ORLANDI, E. P. Análise de Discurso: princípios e procedimentos. Campinas (SP): Pontes, 3. ed., 2001. 


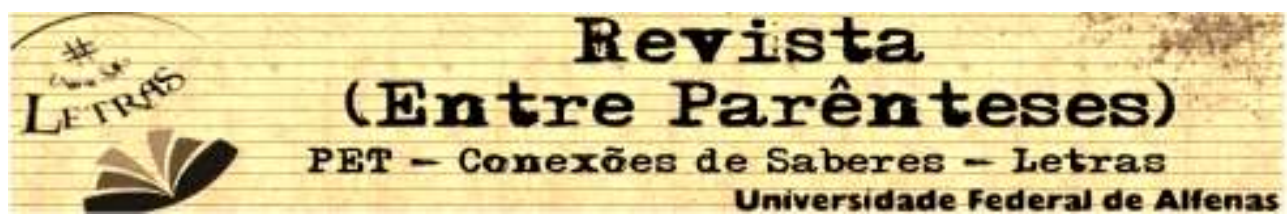

PECHÊUX, M. O discurso: estrutura ou acontecimento. Trad.: Eni Pulcinelli Orlandi. Campinas (SP): Pontes, 1997.

PIRES, V. L.; TAMANINI-ADAMES, F. A. Desenvolvimento do conceito bakhtiniano de polifonia. Estudos Semióticos, vol. 6, n. 2, São Paulo, nov. 2010, p. 66-76. Disponível em:

$<$ http://www.fflch.usp.br/dl/semiotica/es/eSSe62/2010esse62 vlpires fatamanini ada mes.pdf>. Acesso em: 19 nov. 2013. 